\title{
EDUCANDO PARA PARTO ATIVO POR VIA REMOTA: uma realidade no contexto da PANDEMIA
}

\author{
Amanda Paganini Lourencini \\ apaganinilourencini@gmail.com \\ Amanda Barbosa Moraes \\ amandab_moraes@hotmail.com \\ Brenda Costa Prado \\ costaprado.brenda@gmail.com \\ Closeny Maria Soares Modesto \\ soarescloseny@gmail.com \\ Neudson Johnson Martinho \\ neudsonjm@hotmail.com
}

\section{Resumo}

Na década de 70 houve um movimento pela autonomia feminina no parto, para que o ato de parir fosse algo natural e guiado pela mulher/mãe. O Grupo PEMEDUTS/UFMT com o objetivo de socializar saberes e fazeres, realizou oficina voltada para área saúde, com o tema "Parto Ativo Multiprofissional" com expertise no tema. Este estudo é de abordagem qualitativa, sobre ação de extensão com elaboração de e-book. que possibilitou participação ativa e consolidação do saber. A pandemia e o isolamento social devem servir de incentivos para a utilização da extensão como educação em saúde, contribuindo para as mudanças no cenário e do olhar sobre o protagonismo feminino na parição, com a mudança da práxis.

\section{Palavras-chave}

Equipe Multiprofissional; Educação em Saúde; Parto Humanizado. 


\section{Introdução}

Um movimento começa com as primeiras ações. E foi justamente pela conscientização das vantagens do Parto Ativo por algumas mulheres no norte de Londres no final da década de 70 que a tentativa de dar à luz no plano vertical nos hospitais da região se iniciou. Algumas foram encorajadas por obstetras, enquanto outras se depararam com oposição refratária. O Parto Ativo surgiu na década de 70 em Londres, liderado por Janet Balaskas, tendo como fato marcante de sua trajetória inicial uma série de conflitos causados pelo movimento desencadeado por Balaskas na desmistificação dos preconceitos existentes na época, que acabou culminando com a proibição do parto ativo nas instituições de saúde. A idealizadora do movimento e seus apoiadores não se deixaram inibir por esse ato de desumanização da parturição, e a luta continuou fomentada pelo levantamento de uma bandeira em prol do direito das mulheres em decidir sobre o seu parto, que alcançou o seu auge no dia 11 de abril de 1982 quando houve uma manifestação chamada de "Comício pelos direitos de parir", que teve seu início em Londres e em pouco tempo se espalhou para o restante dos país reunindo mais de 6.00 pessoas. Difícil de entender que o fato das mulheres grávidas daquela época causaria tantos conflitos por desejarem "parir em posições verticais" que traziam um melhor conforto por serem mais adequadas fisiologicamente, falando à medida que concordamos com Jones (2017) ao afirmar que

Humanizar o nascimento é garantir o protagonismo para as mulheres, entender o nascimento como um evento social e humano, e não apenas médico é reconhecê-lo como o evento apical da feminilidade, sobre o qual atuam forças sociais, emocionais, psicológicas, afetivas, espirituais e - acima de tudo - é ter uma visão interdisciplinar, observando a devida consideração com os outros atores que fazem parte tanto da cena de parto, como do debate sobre seu significado na cultura (JONES, 2017, PÁG. 15$)^{1}$

Segundo Balaskas (2015), falar em parto ativo é falar sobre a autonomia da mulher, onde são respeitadas suas decisões e escolhas. No parto ativo a mulher segue seu ritmo natural, seus instintos com liberdade de escolhas, fazendo com que ocorra um parto mais rápido e seguro, ocorrendo mudanças de posições e movimentos onde o corpo da mulher é o protagonista da parturição, favorecendo o nascimento (CORREA, 1994). Afirma ainda que a educação das mulheres para o parto ativo contribuirá para diminuir a probabilidade da 
ocorrência de complicações na gravidez, assegurando que esta chegue ao parto em ótimas condições de saúde, além de melhorar e apressar sua recuperação biopsicossocial.

No Brasil o movimento pelo parto ativo ganhou força na década de 90, porém ainda hoje é uma realidade distante, para muitos é considerado utopia, onde vêm a mulher como agente passivo centralizada no foco biologicista, embora a literatura constate que "o parto é um processo fisiológico e natural, que bem conduzido, não precisa de intervenções" (BALASKAS, 2005).

Nesse sentido, uma das alternativas mais importantes para assegurar certa autonomia a mulher gestante perante tal cenário, é a ação educativa (BRENDES, 2015). A educação em saúde ocorre de forma dinâmica e tem o objetivo de capacitar o indivíduo, a fim de promover qualidade de vida e dignidade. Ressalta-se que os participantes de educação em saúde podem aceitar ou negar as mudanças propostas e, assim, as ações devem estimular a indagação e reflexão sobre a temática (MACIEL, 2009; MARTINHO, 2005).

O Grupo Multiprofissional em Educação e Tecnologias em Saúde (PEMEDUTS/UFMT) notou a necessidade em desenvolver este projeto de extensão com interface na pesquisa, intitulado "PRÉ-NATAL HUMANIZADO: EDUCAÇÃO EM SAÚDE PARA O PARTO ATIVO”, aprovado pelo CEP Saúde da UFMT com o parecer nํㅜ 2.406.110.

Frente a situação de pandemia que assola o mundo, as ações do projeto estão sendo realizadas via online. Nesse contexto, realizamos uma oficina virtual para Estudante da Saúde sobre Parto Ativo na perspectiva Multiprofissional, visando efetivar ações de educação em saúde capacitando-os para atuação no projeto.

Este trabalho objetiva relatar uma ação extensionista desenvolvida mediante metodologias remotas (online) e a elaboração de material digital (e-book), como estratégias efetivas no processo educativo de estudantes e profissionais da área da saúde quanto à temática Parto Ativo.

\section{Metodologia}

Trata-se de um estudo descritivo, com abordagem qualitativa, sobre uma ação de extensão realizada por estudantes dos cursos de medicina e serviço social da Universidade Federal do Mato Grosso - UFMT, sob orientação de docentes, como estratégia de implementação do projeto cadastrado no SIEX sob no 2.406 .110 , devidamente aprovado pelo CEP da UFMT por ser um projeto de extensão com interface na pesquisa. 
A ação extensionista foi realizada de maneira remota (online), em formato de oficina, na qual os alunos tiveram a oportunidade de participar em tempo real, tirando suas dúvidas e interagindo, entre os participantes e a convidada. Como efetivação da proposta de educação em saúde para o parto ativo foi elaborado um material de apoio (e-book), previamente disponibilizado nos canais de comunicação digital contendo alguns aspectos considerados essenciais para subsidiar as discussões do tema abordado, no momento síncrono da oficina. A oficina foi ministrada por uma docente convidada do curso de medicina da Universidade Federal de Mato Grosso do Sul, campus de Três Lagoas, a Profa. Dra. Kaelly Virgínia Saraiva, Especialista na área de obstetrícia e parto ativo, além de ter sido a idealizadora do Centro de Parto Normal da Universidade Federal do Ceará, em Fortaleza, no ano de 2000. Para a realização da oficina foi necessário estabelecermos contato com a professora, e compatibilizarmos uma data mais apropriada que pudesse contemplar a disponibilidade de tempo da palestrante e o desenvolvimento das habilidades necessárias, por parte dos integrantes do grupo no manejo de novas tecnologias de informação e comunicação (TICs) e de recursos midiáticos que não são implementados de forma mais sólida nos cursos de graduação.

As atividades de planejamento da oficina e elaboração dos materiais a serem utilizados ocorreram no período de sete de julho a sete de agosto, sendo que para uma melhor organização do trabalho a ser desenvolvido foi elaborado um formulário pelo Google Forms onde os alunos registravam não só as atividades semanais como também as dificuldades que estavam enfrentado e através da socialização de problemas e soluções fomos dando corpo a tão esperada oficina, que de apenas projeto se transformou em realidade coroada de êxitos conforme os resultados pós evento que foram objeto de avaliação pelos participantes.

Os questionários de avaliação pré e pós evento foram disponibilizados virtualmente para aplicação pelo aplicado pelo Google Forms, sendo que todos os participantes, um total de 20 inscritos, responderam aos questionamentos previamente elaborados como estratégia de avaliação do alcance dos objetivos e do índice de satisfação com a realização da oficina, destes, 18 eram acadêmicos dos cursos de medicina, enfermagem e nutrição e 2 profissionais da área da saúde. $65 \%$ dos respondentes se encontravam na faixa etária entre 19 a 24 anos, demonstrando a prevalência de jovens na oficina.

Foi realizada uma pesquisa avaliativa dividida em duas fases, na primeira fase os participantes responderam a um questionário online, via Google Forms, acerca de seus conhecimentos sobre parto ativo, prévios a oficina e na segunda respondiam as mesmas perguntas, só que após o evento. Este questionário teve como objetivo fazer uma analogia 
quanto aos conhecimentos dos participantes antes e depois da oficina, assim como, avaliar se houve impactos positivos com a sua realização.

\section{Resultados e Discussão}

O contexto das discussões sobre parto ativo, na atualidade ocorrem dentro de um cenário ainda muito incipiente de estudos realizados na nossa realidade, assim também como deixam em evidência um cenário de saúde com fragilidades no seu arcabouço no que diz respeito a constituição de redes de serviços que sejam articuladas e constituídas por profissionais atualizados em processos assistenciais de cuidado que assegurem o protagonismo dos atores envolvidos, como é o caso das mulheres grávidas e a efetivação de suas escolhas não só pelo modo como irá parir, mais também onde irá trazer ao mundo o seu concepto. No formulário pré e pós-oficina foi perguntado aos participantes: "Como você classifica seu conhecimento sobre parto ativo?". Eles deveriam classificar de 0 a 5 , sendo 0 nada importante e 5 sendo muito importante.

Nas respostas no período pré-oficina, foram identificados 7 votos para nível 0 do nível de conhecimento sobre parto ativo, 4 votos para nível 1, 3 votos para nível 2, 1 votos para nível 3, 3 votos para nível 4 e 2 votos para nível 5, apresentados no gráfico de barras abaixo (figura 1).

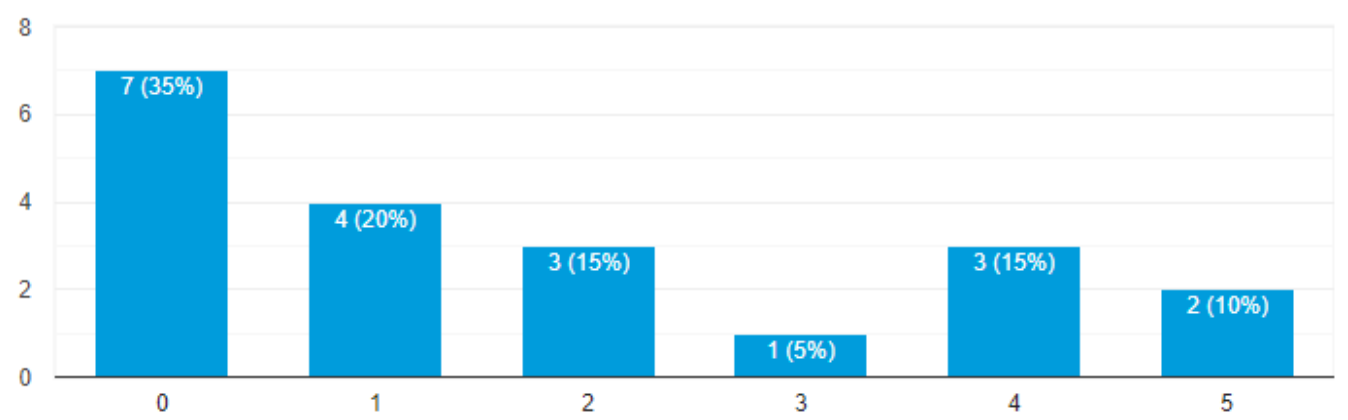

Figura 1: Questionário Pré-oficina: “Como você classifica seu conhecimento sobre parto ativo?". Participante $(\mathrm{N}=20)$ numa escala de 0-5 quanto ao nível de conhecimento

Fonte: Elaboração própria.

Já as respostas pós-oficina foram: 3 votos para nível 3 de conhecimento sobre parto ativo, 12 votos para nível 4 e 5 votos para nível 5, como verifica-se abaixo (figura 2). 
15

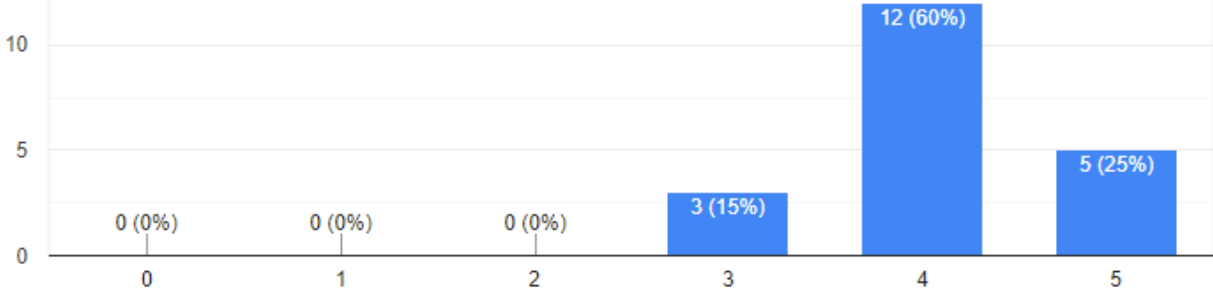

Figura 2: Questionário Pós-oficina: "Como você classifica seu conhecimento sobre parto ativo?". Participante $(\mathrm{N}=20)$.

Fonte: Elaboração própria.

Foi notório que após participação na oficina, $60 \%$ dos participantes consideraram que o seu conhecimento sobre parto ativo era classificado com nível 4 , sendo seguido por $25 \%$ dos participantes que classificaram seu conhecimento sobre parto ativo nível máximo (5). Tal resultado nos leva a inferir que a realização da oficina foi impactante positivamente para aprendizagem dos participantes. Observou-se um aumento notório, visto que da mesma pergunta pré-oficina, o nível de conhecimento mais votado foi 0, no qual obteve 35\%.

Outra pergunta foi: "você entende a importância de uma equipe multiprofissional para o pré natal?" no qual eles deveriam responder "sim", "não" ou “talvez".

$60 \%$ dos participantes responderam "sim", seguido concomitantemente de $20 \%$ para "não" e "talvez", como se pode observar abaixo (figura 3).

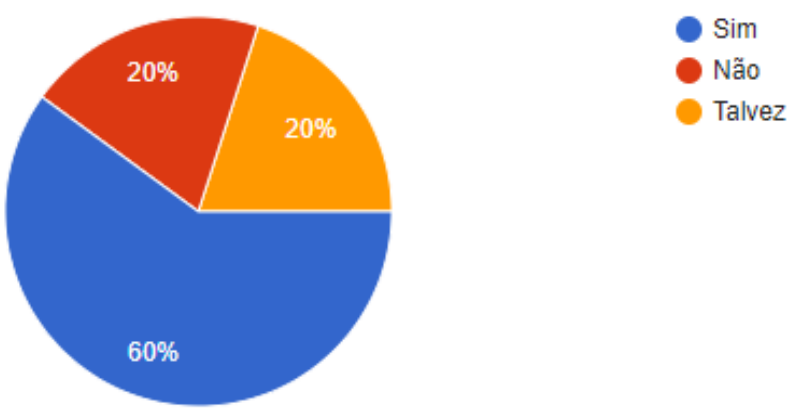

Figura 3: Questionário Pré-oficina: "você entende a importância de uma equipe multiprofissional para o pré natal?". Participante $(\mathrm{N}=20)$.

Fonte: Elaboração própria.

Quando questionados pela mesma pergunta após a oficina, obteve-se unanimidade (100\%) para a resposta "sim", conforme gráfico (figura 4). 


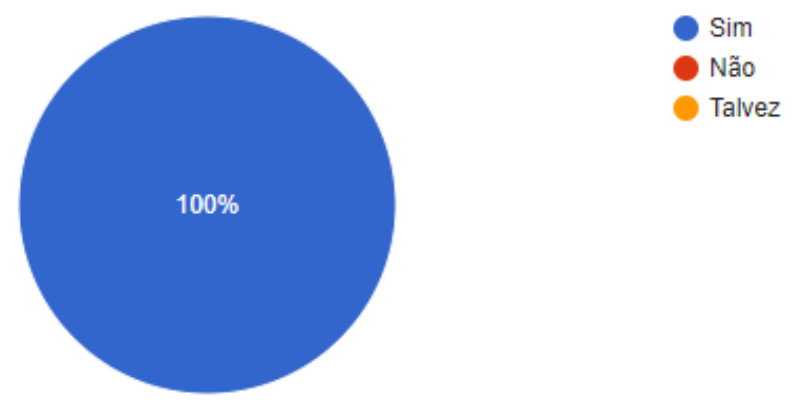

Figura 4: Questionário Pré-oficina: "Você entende a importância de uma equipe multiprofissional para o pré natal?". Participante ( $\mathrm{N}=20)$.

Fonte: Elaboração própria.

Observa-se que depois da oficina, os participantes passaram a entender a importância de uma equipe multiprofissional para o pré-natal como nível máximo (5), sendo que anteriormente à oficina, apenas $60 \%$ votaram nível 5 . Tal resultado retrata extremo êxito para a ação extensionista, visto que a temática multiprofissional para a área da saúde é uma grande lacuna na formação acadêmica.

Quanto ao material digital (e-book) disponibilizado, foi perguntado: "Você já teve acesso a um documento sobre Parto Ativo Multiprofissional para Estudantes da Saúde?", no qual eles deveriam responder "sim" ou "não".

Obteve-se $75 \%$ dos votos para "não", seguido por 50\% para "sim", conforme apresentado no gráfico (figura 5).

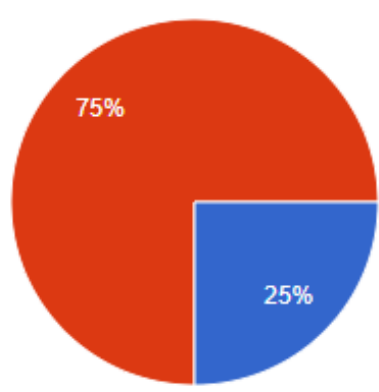

Figura 5: Questionário Pré-oficina: "Você já teve acesso a um documento sobre Parto Ativo Multiprofissional para Estudantes da Saúde?". Participante (N=20).

Fonte: Elaboração própria.

Ao serem questionados: "Você considera que o acesso ao documento sobre "Parto Ativo Multiprofissional para Estudantes da Saúde" agregou no seu conhecimento e aprendizado 
sobre o tema?", obteve-se 95\% para a resposta "sim" e 5\% para "não", conforme gráfico (figura $6)$.

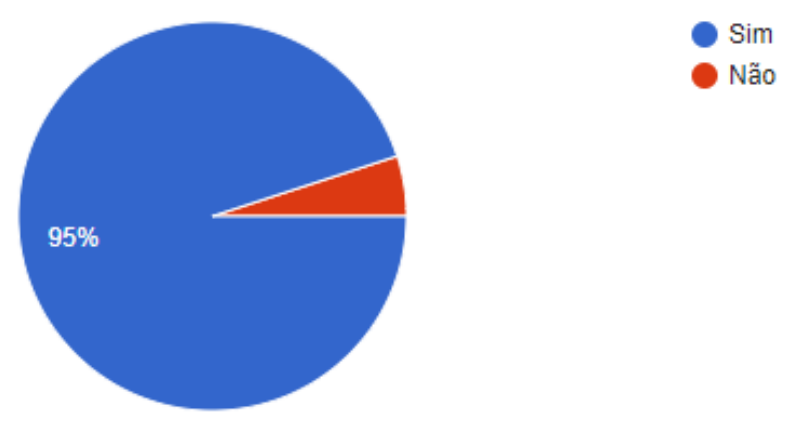

Figura 6: Questionário Pós-oficina: "Você considera que o acesso ao documento sobre "Parto Ativo Multiprofissional para Estudantes da Saúde" agregou no seu conhecimento e aprendizado sobre o tema?". Participante $(\mathrm{N}=20)$.

Fonte: Elaboração própria.

Pode-se concluir, portanto, que o acesso ao material digital (e-book) denominado "Parto Ativo Multiprofissional para Estudantes da Saúde" era um artifício inexistente para 75\% dos participantes, sendo ele um meio eficaz para aprendizado sobre o tema, como foi confirmado por $95 \%$ dos participantes.

\section{Conclusões}

0 Brasil está entre os países campeões na realização de cirurgias cesarianas desnecessárias, de violências obstétricas, não ficando atrás o Estado de Mato Grosso, fenômeno que demonstra a urgente necessidade da implementação das políticas públicas de humanização da assistência, capazes de assegurar às mulheres grávidas o exercício do direito pleno de parir da forma que achar melhor e mais conveniente para o seu contexto social, pessoal e familiar e de projetos de extensão que orientem e viabilizem aprendizagens a estudantes e profissionais da área da saúde, às mulheres e sociedade de uma forma geral quanto a importância da realização de pré-natais que sejam humanizados e eduquem as gestante e sua família quanto a importância do Parto ativo, tanto para saúde da mulher quanto do bebê.

A rede se serviços do Sistema Único de Saúde (SUS) precisa de estratégias de cuidados que possibilitem uma qualificação do pré natal de baixo risco e ou de risco habitual, a serem mediadas pela atuação multiprofissional que pode ter seu início de forma acanhada e dentro de um contexto que envolva minimamente alguns dos profissionais hoje alocados nos 
Núcleos de apoio à saúde da família (NASF) já estruturados em Cuiabá, onde poderia ser escolhido uma Estratégia de Saúde da Família (ESF) que pudesse ser estruturada com a inserção dos alunos de graduação dos cursos que fazem parte da área da saúde como a nutrição, enfermagem, serviço social, medicina, enfermagem, educação física e psicologia com o propósito de implementar ações que servissem de gatilho para a implementação do "Parto Ativo" como incubadora essencial para a mudança da práxis.

Consideramos que mais projetos desta natureza sejam incentivados na UFMT, na Região Centro Oeste e no Brasil. Que a pandemia e o isolamento social não sejam considerados empecilhos, mas, que possa servir de incentivo para utilização de ferramentas viabilizadoras para que a extensão com educação em saúde realizada e alcance cada vez mais a sociedade, como foi evidenciado na ação realizada, contribuindo para as mudanças necessárias no cenário de saúde do país e também na mudança do olhar sobre o protagonismo feminino na parição e também na mudança da práxis dos referidos profissionais.

\section{Referências}

BALASKAS, Janet. Parto Ativo - Guia prático para o parto natural. 3ª edição, São Paulo: Ground, 2005.

MARTINHO, Neudson Johnson. Guia de conduta em Pré-natal: Desenvolvimento de tecnologia em Enfermagem à luz da CIPE - versão alfa. Fortaleza: UFC, 2005. $112 \mathrm{f}$. Dissertação (Mestrado em Enfermagem) - Programa de Pós-Graduação em Enfermagem, Faculdade de Farmácia, Odontologia e Enfermagem (FFOE), Universidade Federal do Ceará, 2005.

. BRENDES, A., PASSOS, L. A. Educação em saúde, movimentos sociais em luta- Tecendo redes, articulando saberes e práticas em favor da vida. In: SILVA, M. G. M., SANTOS, N. C. S. Pesquisa em educação e saúde: conexões e horizontes. Cuiabá-MT: Ed. UFMT, 2015.

MACIEL, Marjorie Ester Dias. Educação em Saúde: Conceitos e Propósitos. Rev. Cogitare Enfermagem, 2009. Out/Dez; 14(4):773-6.

CORREA, M. D. Noções práticas de obstetrícia. 11. Ed. Belo Horizonte, MG: Coopmed, 1994. 
Educating for active delivery by remote: a reality in the pandemic context.

\begin{abstract}
In the 70 s there was a movement for female autonomy in childbirth, so that the act of giving birth was something natural and guided by the woman / mother. The PEMEDUTS / UFMT Group, with the objective of socializing knowledge and practices, held a workshop focused on the health area, with the theme "Active Multiprofessional Childbirth" with expertise in the theme. This study has a qualitative approach, about extension action with the elaboration of an e-book. that enabled active participation and consolidation of knowledge. The pandemic and social isolation should serve as incentives for the use of extension as health education, contributing to changes in the scenario and the look at the female protagonism in childbirth, with the change of praxis.
\end{abstract}

\section{Keywords}

Multiprofessional team; Health Education; Humanized Childbirth.

\section{Educar para la entrega activa a distancia: una realidad en el contexto de pandemia.}

\section{Resumen}

los años 70 surgió un movimiento por la autonomía femenina en el parto, por lo que el acto de dar a luz era algo natural y guiado por la mujer / madre. El Grupo PEMEDUTS / UFMT, con el objetivo de socializar conocimientos y prácticas, realizó un taller enfocado en el área de salud, con el tema "Parto Activo Multiprofesional" con experiencia en el tema. Este estudio tiene un enfoque cualitativo, sobre la acción de extensión con la elaboración de un libro electrónico. que permitió la participación activa y la consolidación de conocimientos. La pandemia y el aislamiento social deben servir como incentivo para el uso de la extensión como educación para la salud, contribuyendo a cambios en el escenario y la mirada al protagonismo femenino en el parto, con el cambio de praxis.

\section{Palabras clave}

Equipo multiprofesional; Educación para la salud; Parto humanizado. 